\title{
1,4-bis(2,2-diphenylethenyl)benzene as an efficient emitting material for organic light emitting diodes
}

\author{
Larysa Fenenko ${ }^{1,2}$, Guoliang $\mathrm{Mao}^{3}$, Akihiro Orita ${ }^{3}$, Junzo Otera ${ }^{3}$, Petro Smertenko ${ }^{2}$, Georgi Svechnikov², \\ Jun-ichi Nishide ${ }^{4}$, Hiroyuki Sasabe ${ }^{4}$, Chihaya Adachi ${ }^{1}$ \\ ${ }^{1}$ Center for Future Chemistry, Kyushu University, 744 Motooka, Nishi, Fukuoka 819-0395, Japan \\ ${ }^{2}$ V. Lashkaryov Institute of Semiconductor Physics, NAS of Ukraine, Department of Optoelectronics, 41, prospect \\ Nauky, 03128 Kyiv, Ukraine \\ ${ }^{3}$ Department of Applied Chemistry, Okayama University of Science, 1-1 Ridai, Okayama 700-0005, Japan \\ ${ }^{4}$ Chitose Institute of Science and Technology (CIST), 758-65 Bibi, Chitose, Hokkaido 066-8655, Japan \\ *Corresponding author: e-mail: fenenko@yahoo.com
}

\begin{abstract}
We report on the photophysical properties of 1,4-bis(2,2-diphenylethenyl)benzene (PEB) in a solution and a solid state. A poor blue photoluminescence efficiency of PEB in a solution dramatically increases in the deposited film. We explain such properties in terms of molecular dynamics and degrees of intramolecular freedom in various molecular environments. $\mathrm{PEB}$ as an electron-transport and emitting layer in organic light-emitting diodes (OLEDs) shows bright blue-green electroluminescence (EL) with the peak wavelength at $\lambda_{\max } \sim 495 \mathrm{~nm}$. The maximum external EL quantum efficiency of $\eta_{\mathrm{EL}}=2.5 \%$ and maximum luminance of $41600 \mathrm{~cd} / \mathrm{m}^{2}$ in the optimized device were obtained, indicating that PEB possesses superior electron-transport ability.
\end{abstract}

Keywords: electroluminescence, electrical transport characteristics, OLED, 1,4-bis(2,2diphenylethenyl)benzene (PEB).

Manuscript received 22.12.06; accepted for publication 26.03.07; published online 01.06.07.

\section{Introduction}

Organic light emitting diodes (OLEDs) have become one of the most attractive research areas in recent years. Wide possibilities of various molecular structures through organic synthesis, simple and low temperature processability and low cost, attributed to organic materials, show their high potential and promising feature as a next-generation display [1-4]. Since the organic multilayer electroluminescence (EL) diode was reported in 1987 [5], the OLED characteristics have been progressively improved. Various device structures, organic materials and fabrication techniques have been widely developed [6-8].

Among various emitting materials, one of the promising candidates is an arylethene and stilbene based $\pi$-conjugated system [9-14]. Some of $\pi$-conjugated compounds such as stilbene and poly(arylenevinylene)s (1,2-diarylethene-based $\pi$-systems) have already revealed their high potential as the OLED materials [9, 15-18] due to their excellent fluorescence properties [9]. Many arylethene derivatives have photoluminescence
(PL) in a visible region; the PL spectrum and the PL efficiency significantly depend on the substituents and their position and these derivatives emit intense PL even in a solid state [9, 19-21].

The blue-green emitting 1,4-bis(2,2-diphenylethenyl)benzene (PEB) shown in Fig. 1 is the simplest material in this family containing stylbene units and can be a good model compound to understand basic photophysical and electrical properties. As it was reported before, PEB is highly fluorescent and can be used as a dopant in blue emitting OLEDs [16, 22-23]. OLED with PEB dispersed into a polystyrene (PS) matrix showed pure blue emission with the external EL quantum efficiency of $\eta_{\mathrm{EL}}=0.25 \%$ [22]. Further, OLED using PEB blended with rubrene in a PS matrix demonstrated white emission with $\eta_{\mathrm{EL}}=0.3 \%$ [23]. Although the PL efficiency of PEB in a solid film was found to be high [16], the EL efficiencies of OLEDs with the spin-coated emitting layer containing PEB were rather low [22-23].

In this work, we report on the fundamental photophysical properties of PEB in a solution and a solid state. We also study the EL and carrier transport 
characteristics of PEB using various OLED structures. A high efficiency OLED with PEB as an electron-transport and emitting layer is demonstrated.

\section{Experimental section}

PEB was synthesized according to the preparation method described below. All reactions were carried out under an atmosphere of nitrogen with freshly distilled solvents, unless otherwise noted. Silica gel (Daiso gel IR-60) was used for column chromatography. NMR spectra were recorded on JEOL Lambda 500 instrument. To a DMF solution $(25 \mathrm{~mL})$ of terephthalaldehyde ( $268 \mathrm{mg}, 2.0 \mathrm{mmol}$ ), $0.663 \mathrm{~g}$ of dimethyl diphenylmethylphosphonate and $0.449 \mathrm{~g}$ of potassium t-butoxide were added. The solution was stirred at room temperature for 12 hours. After being transferred to a separation funnel, ethyl acetate was added to mixture. $\mathrm{NaCl}$ solution was used to wash the organic phase for 3 times to remove DMF. Then, the organic layer was washed with brine and dried over $\mathrm{MgSO}_{4}$. After evaporation, the residue was subjected to column chromatography on silica gel (hexane / $\mathrm{CH}_{2} \mathrm{Cl}_{2}=10: 1$ ) to give 1,4-bis(2,2-diphenylethenyl)benzene (PEB) $(0.617 \mathrm{~g}, 71 \%)$ as yellow solid. H NMR $(500 \mathrm{MHz}$, $\left.\mathrm{CDCl}_{3}\right) \delta 6.79(\mathrm{~s}, 4 \mathrm{H}), 6.86(\mathrm{~s}, 2 \mathrm{H}), 7.14-7.20(\mathrm{~m}, 4 \mathrm{H})$, 7.25-7.34 (m, 16H). C NMR (125 MHz, $\left.\mathrm{CDCl}_{3}\right) \delta$ 127.42 , 127.45, 127.57, 127.86, 128.16, 128.60, 129.15, $130.35,135.88,140.35,142.49,143.46$.

To investigate the molecular aggregation properties of PEB, the degassed solutions with various PEB concentrations of $10^{-6} \sim 10^{-2} \mathrm{M}$ in dehydrated chloroform $\left(\mathrm{CHCl}_{3}\right)$ and toluene $\left(\mathrm{CH}_{3} \mathrm{C}_{6} \mathrm{H}_{5}\right)$ were prepared for PL measurements. Neat PEB films were deposited in vacuum $\left(10^{-4} \mathrm{~Pa}\right)$ on pre-cleaned quartz, glass and ITO substrates, respectively. The substrates were cleaned using a standard cleaning procedure and exposed to UVozone before vacuum deposition. The thicknesses of the deposited films were measured with Stylus Profiler DEKTAK 6M.

The highest occupied molecular orbital (HOMO) level of the deposited films was measured with an ultraviolet photoelectron spectroscopy (AC-1, Riken Keiki Co.). The absorption spectra of the degassed solutions and deposited films were recorded using a UVVIS-NIR recording spectrophotometer UV-3100 (Shimadzu Co.). The PL spectra were measured using Spectrofluorometer FP-6500-A-51 (Jasco Co.). The absolute PL efficiency $\left(\Phi_{f}\right)$ of degassed solutions and neat films under argon flow was measured using an integrating sphere [24] with $325 \mathrm{~nm}$ excitation source (Xe lamp) and multi-channel spectrometer (Hamamatsu PMA-11) as the optical detector.

To understand the carrier transport and EL properties of PEB, we prepared three types of OLED structures (Fig. 1): Type (I): $\operatorname{ITO}(110 \mathrm{~nm}) \quad / \quad \alpha-$ $\operatorname{NPD}(50 \mathrm{~nm})$ / PEB(50 nm) / $\mathrm{Mg}: \operatorname{Ag}(100 \mathrm{~nm})$ / $\operatorname{Ag}(20 \mathrm{~nm})$; Type (II): ITO(110 nm) / $\alpha-\operatorname{NPD}(50 \mathrm{~nm}) /$
PEB(20 nm) / Bphen(30 nm) / Mg:Ag(100 nm) / $\operatorname{Ag}(20 \mathrm{~nm})$; and Type (III): ITO(110nm) / $\alpha$ $\mathrm{NPD}(50 \mathrm{~nm}) \quad / \quad \operatorname{PEB}(10 \mathrm{~nm}) \quad / \quad \mathrm{Alq}_{3}(50 \mathrm{~nm})$ / $\mathrm{Mg}: \operatorname{Ag}(100 \mathrm{~nm}) \quad / \quad \operatorname{Ag}(20 \mathrm{~nm})$. Here, 4,4'-bis[N-(1naphtyl)-N-phenyl-amino]biphenyl $(\alpha-N P D)$ as a holetransport layer (HTL), aluminum (III) tris(8hydroxyquinoline) ( $\left.\mathrm{Alq}_{3}\right)$ as an electron-transport layer (ETL), and 4,7-diphenyl-1,10-phenanthroline (Bphen) as an ETL and hole-blocking (HBL) layer were used for OLEDs (Fig. 1). A magnesium silver (Mg:Ag) alloy layer (10:1) capped with a silver layer was deposited on the top of the organic layers. Current density-voltageluminance (DVL) characteristics were measured using a semiconductor parameter analyzer (Agilent, HP4155C) with an optical power meter (Newport, Model 1835-C).

\section{Results and discussion}

\subsection{Photoluminescent properties of PEB in a solution and a solid state}

Table and Fig. 2 summarize the optical properties of PEB in a neat film and in solutions with the PEB concentrations of $10^{-6} \sim 10^{-2} \mathrm{M}$ in chloroform and toluene, respectively. These PEB solutions indicate strong absorption with the maxima at $\lambda_{a, \max } \sim 355 \mathrm{~nm}$ corresponding to the $0 \rightarrow 0 *$ transition. The absorption spectrum of the $50 \mathrm{~nm}$-thick PEB film showed the identical absorption maximum at $\lambda_{a, \max }=356 \mathrm{~nm}$ (Fig. 2).

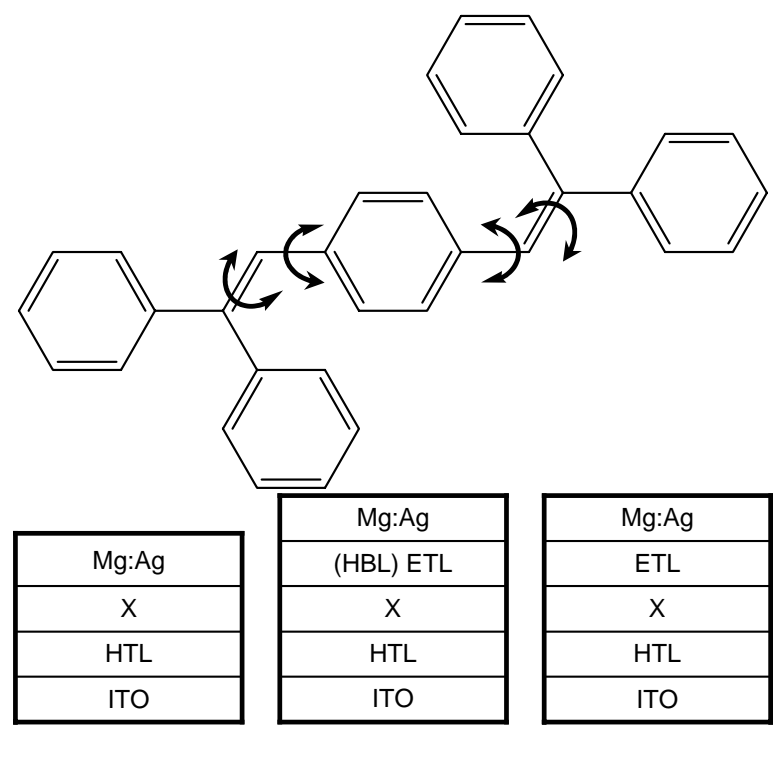

(l)

(II)

(III)

Fig. 1. PEB molecular structure with indication of possible intermolecular rotations around the single and double bonds. The types of OLED structures: (I) - ITO $(110 \mathrm{~nm}) / \alpha$ $\mathrm{NPD}(50 \mathrm{~nm}) / \operatorname{PEB}(50 \mathrm{~nm}) / \mathrm{Mg}: \operatorname{Ag}(100 \mathrm{~nm}) / \operatorname{Ag}(20 \mathrm{~nm})$; (II) - ITO(110 nm) / $\alpha-\mathrm{NPD}(50 \mathrm{~nm}) \quad / \quad \operatorname{PEB}(20 \mathrm{~nm})$ / Bphen $(30 \mathrm{~nm}) \quad / \quad \mathrm{Mg}: \operatorname{Ag}(100 \mathrm{~nm}) \quad / \quad \operatorname{Ag}(20 \mathrm{~nm}) ; \quad$ (III) $\operatorname{ITO}(110 \mathrm{~nm}) / \alpha-\mathrm{NPD}(50 \mathrm{~nm}) / \operatorname{PEB}(10 \mathrm{~nm}) / \operatorname{Alq}_{3}(50 \mathrm{~nm}) /$ $\mathrm{Mg}: \operatorname{Ag}(100 \mathrm{~nm}) / \operatorname{Ag}(20 \mathrm{~nm})$. 
Table. Photophysical properties of PEB in solution and deposited film.

\begin{tabular}{|c|c|c|c|c|c|}
\hline & \multicolumn{3}{|c|}{ Solution } & \multirow[t]{2}{*}{ Neat film } & \multirow{2}{*}{$\begin{array}{c}\text { X mol \% PEB: CBP } \\
\text { (doped film) }\end{array}$} \\
\hline & $\begin{array}{c}\text { Molar } \\
\text { concentration (M) } \\
\end{array}$ & In chloroform & $\begin{array}{c}\text { In } \\
\text { toluene }\end{array}$ & & \\
\hline HOMO (eV) & & & & 5.8 & \\
\hline LUMO (eV) & & & & 2.9 & \\
\hline$E_{g}(\mathrm{eV})$ & $\begin{array}{l}10^{-6} \\
10^{-5} \\
10^{-4} \\
10^{-3} \\
10^{-2}\end{array}$ & $\begin{array}{l}3.1 \\
3.1 \\
3.1 \\
2.9 \\
2.8\end{array}$ & $\begin{array}{l}3.1 \\
3.1 \\
3.1 \\
3.0 \\
3.0\end{array}$ & 2.9 & \\
\hline$\Phi_{\mathrm{f}}(\%)$ & $\begin{array}{l}10^{-6} \\
10^{-5} \\
10^{-4} \\
10^{-3} \\
10^{-2}\end{array}$ & $\begin{array}{l}4.5 \pm 0.5 \\
4.0 \pm 0.5 \\
4.0 \pm 0.5 \\
4.0 \pm 0.5 \\
3.5 \pm 0.5\end{array}$ & $\begin{array}{l}21.0 \pm 0.5 \\
18.0 \pm 0.5 \\
18.0 \pm 0.5 \\
17.5 \pm 0.5 \\
17.5 \pm 0.5\end{array}$ & $57.0 \pm 0.5$ & $\begin{array}{c}89.0 \pm 0.5^{*} \\
90.5 \pm 0.5^{* *}\end{array}$ \\
\hline$\eta_{\mathrm{EL}}(\%)$ & & & & $\begin{array}{c}0.012 \text { (I) } \\
2.5 \text { (II) } \\
1.1 \text { (III) }\end{array}$ & $\begin{array}{c}1.1 *(\mathrm{II}) \\
1.1 * *(\mathrm{II})\end{array}$ \\
\hline$\lambda_{a, \max }(\mathrm{nm})$ & & 354 & 358 & 356 & $\begin{array}{l}359 * \\
359 * *\end{array}$ \\
\hline$\lambda_{f, \max }(\mathrm{nm})$ & $\begin{array}{c}10^{-6} \\
10^{-5}-10^{-2}\end{array}$ & $\begin{array}{l}456,467 \\
467 \sim 470\end{array}$ & $\begin{array}{c}452,468 \\
468\end{array}$ & 471 & $\begin{array}{c}471 * \\
471 * *\end{array}$ \\
\hline$\lambda_{\mathrm{EL}, \max }(\mathrm{nm})$ & & & & $\begin{array}{l}492(\mathrm{I}) \\
497 \text { (II) } \\
493 \text { (III) }\end{array}$ & $\begin{array}{c}477 *(\mathrm{II}) \\
484 * *(\mathrm{II})\end{array}$ \\
\hline
\end{tabular}

(I), (II) and (III) denote type of the OLED structures.

* 0.23 mol. \%; ** 4.70 mol. \%

In a diluted chloroform or toluene solutions of $10^{-6} \mathrm{M}$, PEB showed blue fluorescence with vibronic structures having two PL maxima at $\lambda_{f, \max } \sim 454 \mathrm{~nm}$ and $\sim 467 \mathrm{~nm}$ corresponded to the $0^{*} \rightarrow 0$ and $0^{*} \rightarrow 1$ transitions, respectively, and a weak shoulder at $\lambda_{f} \sim 494 \mathrm{~nm}\left(0^{*} \rightarrow 2\right.$ transition $)$. With an increase of the PEB concentration, a slight red shift of the PL peaks was observed. The PL spectra of the $10^{-5} \sim 10^{-2} \mathrm{M}$ solutions showed the PL maximum corresponding to the $0^{*} \rightarrow 1$ transition and also two shoulders at 456 and $494 \mathrm{~nm}$. Further, the PL spectrum of the PEB neat film showed more intense red shift compared with those of the spectra in the $10^{-5} \sim 10^{-2} \mathrm{M}$ solutions. The film showed bright blue-greenish emission with a main maximum at $\lambda_{f, \max }=471 \mathrm{~nm}\left(0^{*} \rightarrow 1\right.$ transition $)$ and two shoulders at $\sim 456 \mathrm{~nm} \quad\left(0^{*} \rightarrow 0\right.$ transition $)$ and $493 \mathrm{~nm}\left(0^{*} \rightarrow 2\right.$ transition).

The PL efficiencies of PEB in the $10^{-6} \sim 10^{-2} \mathrm{M}$ chloroform solutions were as low as $\Phi_{f}=3 \sim 5 \%$ and was almost independent on the concentration (Table). On the other hand, the PL efficiencies of PEB in the $10^{-6} \sim 10^{-2} \mathrm{M}$ toluene solutions showed much higher values of $\Phi_{f}=17 \sim 21 \%$ and a slight decrease of the PL efficiency with an increase of the concentration. On the other hand, the PL efficiency of the deposited film was $\Phi_{f}=57 \%$, indicating dramatic increase in the solid state compared with those in the solutions. This can be explained in terms of degrees of the intramolecular freedom of PEB in the solutions and solid state. PEB can be well dissolved in a chloroform solution and have a freedom in the intramolecular rotations as shown in Fig. 1. PEB contains stilbene units which can transform from trans to cis and vice versa under the optical excitation. The trans-configuration of stilbene is radiative, while cis-configuration is completely nonemissive. As it was found before [22], the trans-trans configuration in PEB is optically most emissive, although it can be flipped into less emissive cis-trans or cis-cis PEB configurations under the optical excitation. Thus, the prevention of the intramolecular rotations and stabilization of the trans-configuration are necessary to obtain high PL efficiency. In case of the toluene solution, we suppose that PEB have less freedom for the intramolecular rotation due to the higher viscosity of toluene $\left(\delta=0.68\right.$ Centistokes at $\left.20^{\circ} \mathrm{C}\right)$ compared with chloroform $\left(\delta=0.38\right.$ Centistokes at $\left.20^{\circ} \mathrm{C}\right)$.

To confirm the above consideration, we prepared the "solid solution" of a co-deposited film of 4,4'-N,N'- 
dicarbazole-biphenyl (CBP) doped with $1 \sim 2 \mathrm{wt} \%$ PEB. The PL spectrum of $1 \sim 2 \mathrm{wt} \%$ PEB: CBP co-deposited film was similar to those in the chloroform and toluene solutions, demonstrating the same maximum at $\lambda_{\text {f,max }}=$ $471 \mathrm{~nm}$ and two weak shoulders at 456 and $494 \mathrm{~nm}$, respectively. It indicates that the PEB molecules are well dispersed in the CBP host matrix and no PEB molecular aggregation occurs. The PL efficiency was significantly high compared with these in the solutions and the neat film, showing $\Phi_{f}=(89 \sim 91) \pm 0.5 \%$ (Table). Thus, the CBP host matrix well prevents the intramolecular rotation in PEB, leading to the significant increase of the radiative decay process.

\subsection{Electroluminescent properties of PEB}

All OLEDs showed blue-green EL with the maximum at $\lambda_{\mathrm{EL}, \max }=492 \mathrm{~nm}$ corresponding to the $0^{*} \rightarrow 2$ transition

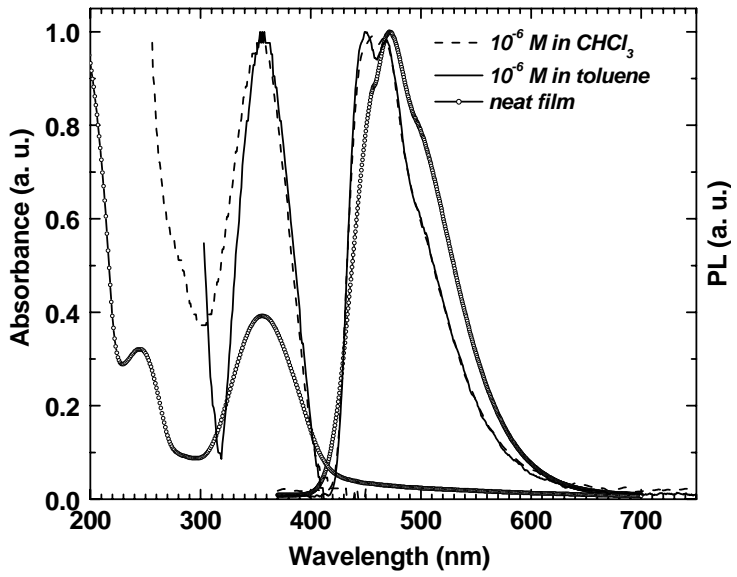

Fig. 2. Absorption and PL spectra of PEB in a neat film and in $10^{-6} \mathrm{M}$ chloroform and toluene solutions.

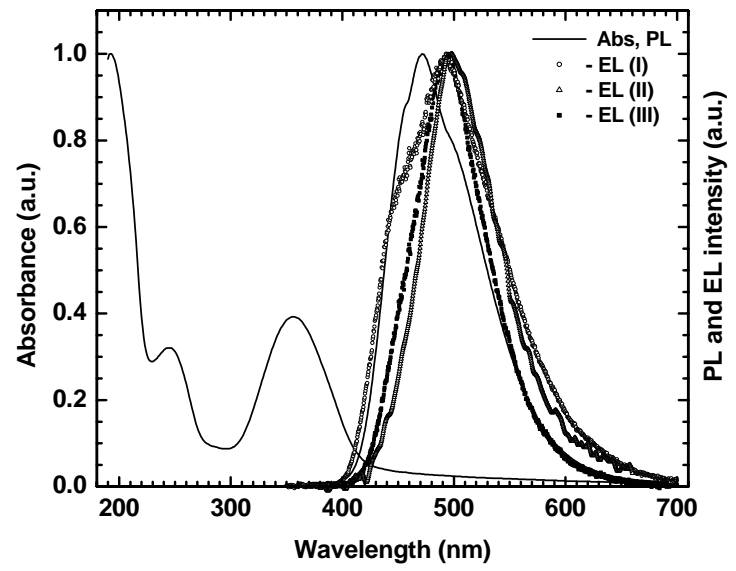

Fig. 3. EL spectra in OLED devices (I, II and III), and PL and absorption spectra of PEB in a neat film.
(Fig. 3). OLEDs with the Type (I) structure showed inferior device characteristics. The low external EL quantum efficiency of $\eta_{\mathrm{EL}}=0.012 \%$ with maximum luminance of $\sim 31 \mathrm{~cd} / \mathrm{m}^{2}$ and poor reproducibility were observed due to the crystallization of the PEB layer during the metal deposition (Figs 3-5). Also, relatively high energy barrier of $\sim 0.85 \mathrm{eV}$ at the $\mathrm{PEB} / \mathrm{MgAg}$ interface may limit efficient electron injection (Fig. 4).

The OLEDs of Type (II) with Bphen as an additional electron-transport and hole-blocking layer showed good reproducibility and pronounced OLED characteristics with $\eta_{\mathrm{EL}}=2.5 \%$ and the maximum luminance of $41600 \mathrm{~cd} / \mathrm{m}^{2}$ (Figs. 4 and 5). The EL spectrum showed the maximum at $\lambda_{\mathrm{EL}, \max }=493 \mathrm{~nm}$ corresponding to the $0^{*} \rightarrow 3$ transition in PEB (Fig. 3). Here, we observed no crystallization of the PEB layer due to the presence of the overlaid Bphen layer. The small electron injection barrier of $\Delta E=0.1 \mathrm{eV}$ from

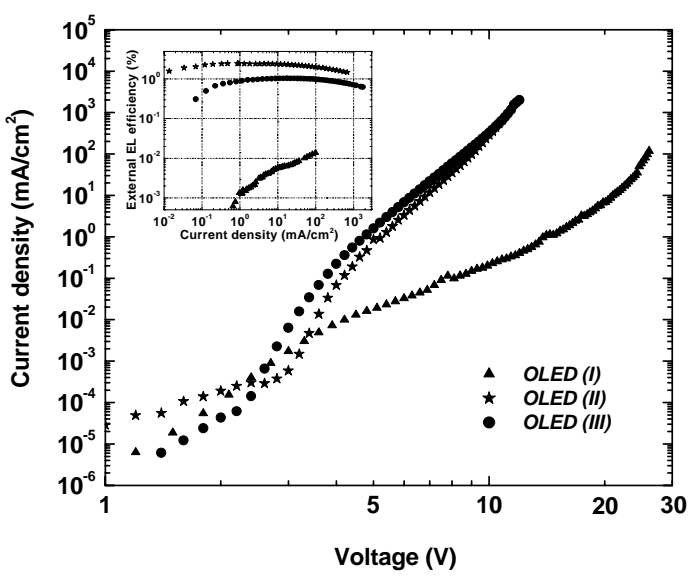

Fig. 4. Current density-voltage (DV) characteristics of OLEDs (I, II and III). The corresponding external EL efficiency-current density $\left(\eta_{\mathrm{EL}}-\mathrm{J}\right)$ characteristics are shown in the insert.

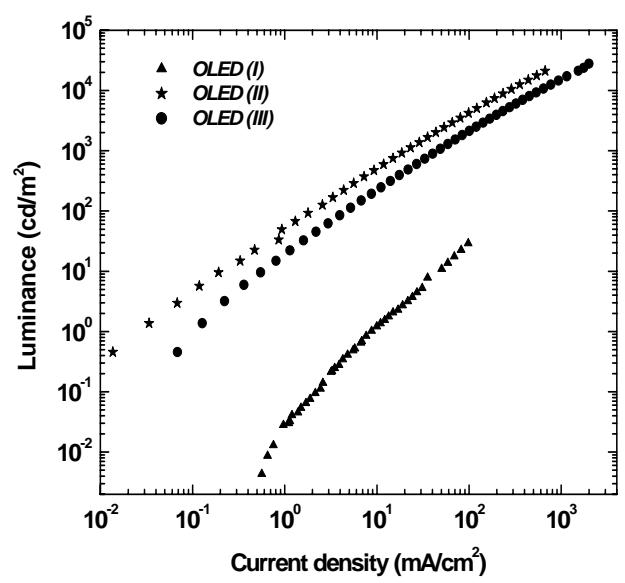

Fig. 5. Luminance-current density characteristics of OLEDs (I, II and III). 


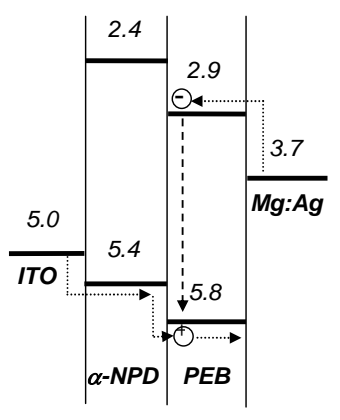

(a)

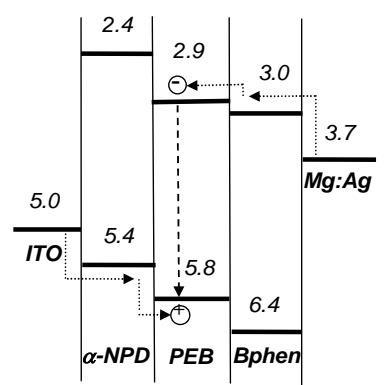

(b)

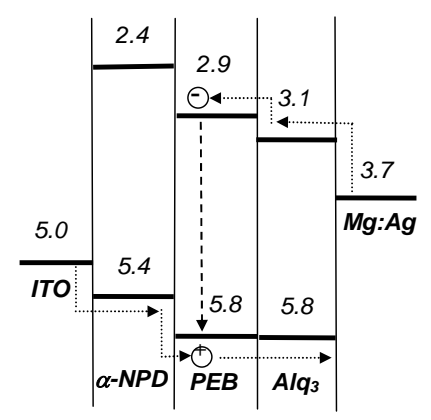

(c)

Fig. 6. Energy diagrams in OLEDs (I (a), II (b) and III (c)).

Bphen into the PEB layer would also provide efficient electron injection (Fig. 6b). To clarify the major carriers in PEB, Type (III) OLED having an $\mathrm{Alq}_{3}$ ETL was examined (Fig. 6c). The EL spectrum was similar to the Type (II) devices, showing the greenish emission with the maximum at $493 \mathrm{~nm}$, indicating that EL is due to PEB layer, since the $\mathrm{Alq}_{3}$ emission locates at $\lambda_{\mathrm{EL} \text {,max }}$ $\sim 510 \mathrm{~nm}$. Thus, we can conclude that the PEB layer efficiently transports electrons.

\section{Conclusions}

The photophysical and EL properties of PEB were investigated. The very weak blue PL of PEB in a solution was dramatically increased in a solid state. We explained such PEB behavior in the terms of degrees of freedom in the intramolecular rotations between cis- and trans-configuration. The prevention of the intramolecular rotations leads to the dramatic increase of $\Phi_{f}$. The OLEDs with PEB as an emitting layer showed bluegreenish EL with the maximum $\eta_{\mathrm{EL}}=2.5 \%$. PEB was identified as an efficient electron-transport and emitting material in OLEDs.

\section{Acknowledgments}

We are very grateful to the 21 st Century COE program of "Molecular Informatics" for financial support of this study.

\section{References}

1. B.W. D'Andrade, S.R. Forrest, White organic light emitting devices // Adv. Mat. 16, p. 1585-1595 (2004).

2. G.L. Tu, C.Y. Mei, Q.G. Zhou, Y.X. Cheng, Y.H. Geng, L.X. Wang, D.G. Ma, X.B. Jing, F.S. Wang, Highly efficient pure-white-light-emitting diodes from a single polymer: polyfluorene with naphthalimide moieties // Adv. Funct. Mat. 16, p. 101-106 (2006).

3. Z. Wu, S. Chen, H. Yang, Y. Zhao, J. Hou, S. Liu, Top-emitting organic light-emitting devices based on silicon substrate using Ag electrode // Semicond. Sci. Technol. 19, p. 1138-1140 (2004).

4. A. Misra, P. Kumar, M.N. Kamalasanan, S. Chandra, White organic LEDs and their recent advancements // Semicond. Sci. Techn. 21, R35R47 (2006).

5. C.W. Tang, S.A. VanSlyke, Organic electroluminescent diodes // Appl. Phys. Lett. 51, p. 913915 (1987).

6. J. Shinar, Organic light-emitting devices, A Survey, AIP Press, New York, 2004.

7. Z.Y. Xie, J.S. Huang, C.N. Li, S.Y. Liu, Y. Wang, Y.Q. Li, J.C. Shen, White light emission induced by confinement in organic multiheterostructures // Appl. Phys. Lett. 74, p. 641-643 (1999).

8. P.E. Burrows, S.R. Forrest, S.P. Sibley, M.E. Thompson, Color-tunable organic lightemitting devices // Appl. Phys. Lett. 69, p. 29592961 (1996).

9. S. Tokito, T. Iijima, T. Tsuzuki, F. Sato, Highefficiency white phosphorescent organic lightemitting devices with greenish-blue and redemitting layers // App. Phys. Lett. 83, p. 2459-2461 (2003).

10. Y. San, N.C. Giebink, H. Kanno, B. Ma, M.E. Thompson, S.R. Forrest, Management of singlet and triplet excitons for efficient white organic light-emitting devices // Nature 440, p. 908-912 (2006).

11. Y.-J. Tung, T. Ngo, M. Hack, J. Brown, N. Koide, Y. Nagara, Y. Kato, H. Ito, A high efficiency phosphorescent white OLED for LCD backlight and display applications // Proc. Soc. Inform. Display 35, p. 48-51 (2004).

12. V. Savvate'ev, J.H. Zou, J. Shinar, K. Christensen, W. Oldham, L.J. Rothberg, Z. Chen-Esterlit, R. Kopelman, Nanosecond transients in the electroluminescence from multilayer blue organic light-emitting devices based on 4,4' bis(2,2' diphenyl vinyl)-1,1'-biphenyl // Appl. Phys. Lett. 76, p. 1501-1503 (2000).

13. Y.-S. Huang, J.-H. Jou, W.-K. Weng, J.-M. Liu, High-efficiency white organic light-emitting devices with dual doped structure // Appl. Phys. Lett. 80, p. 2782-2784 (2002). 
14. U. Mitschke, P. Bauerle, The electroluminescence of organic materials // J. Mater. Chem. 10, p. 14711507 (2000).

15. A. Mishra, P. K. Nayak, D. Ray, M.P. Patankar, K.L. Narasimhan, N. Periasamy, Synthesis and characterization of spin-coatable tert-amine molecules for hole-transport in organic lightemitting diodes // Tetrahed. Lett. 47, p. 4715-4719 (2006).

16. K. Itami, Y. Ohashi, J.-I. Yoshida, Triarylethenebased extended $\pi$-systems: programmable synthesis and photophysical properties // J. Org. Chem. 70, p. 2778-2792 (2005).

17. C. Adachi, T. Tsutsui, S. Saito, Blue light-emitting organic electroluminescent devices // Appl. Phys. Lett. 56, p. 799-801 (1990).

18. C. Hosokawa, H. Higashi, H. Nakamura, T. Kusumoto, Highly efficient blue electroluminescence from a distyrylarylene emitting layer with a new dopant // Appl. Phys. Lett. 67, p. 3853-3855 (1995).

19. R.H. Friend, R.W. Gymer, A.B. Holmes, J.H. Burroughes, R.N. Marks, C. Taliani, D.D.C. Bradley, D.A. Dos Santos, J.L. Bredas, M. Longdlund, W.R. Salaneck, Electroluminescen- ce in conjugated polymers // Nature 397, p. 121128 (1999).

20. J.L. Segura, N. Martin, Functionalized oligoarylenes as building blocks for new organic materials // J. Mater. Chem. 10, p. 2403-2435 (2000).

21. R.E. Martin, F. Diederich, Linear monodisperse $\pi$ conjugated oligomers: model compounds for polymers and more // Angew. Chem., Int. Ed. 38, p. 1350-1377 (1999).

22. J.P. Yang, P.L. Heremans, R. Hoefnagels, W. Tachelet, P. Dieltiens, F. Blockhuts, H. J. Geise, G. Borghs, Blue organic light-emitting diode using 1,4-bis(1,1-diphenyl-2-ethenyl)benzene as an emitter // Synth. Met. 108, p. 95-100 (2000).

23. J.P. Yang, Y.D. Jin, P.L. Heremans, R. Hoefnagels, P. Dieltiens, F. Blockhuys, H.J. Geise, M. Van der Auwerarer, G. Borghs, White light emission from a single layer organic light emitting diode fabricated by spincoating // Chem. Phys. Lett. 325, p. 251-256 (2000).

24. J.E. Gano, D.J. Osborn, N. Kodali, P. Sekher, M. Liu, E.D. Luzik, Synthesis of twist-twist $\pi$ conjugated di-sec-alkylstilbenes and stilbene polymer // J. Org. Chem. 68, p. 3710-3713 (2003). 